\title{
Contextual conditioning in rats as an animal model for generalized anxiety disorder
}

\author{
Laura Luyten - Debora Vansteenwegen • \\ Kris van Kuyck • Loes Gabriëls • Bart Nuttin
}

Published online: 8 February 2011

(C) Psychonomic Society, Inc. 2011

\begin{abstract}
Animal models of psychiatric disorders are important translational tools for exploring new treatment options and gaining more insight into the disease. Thus far, there is no systematically validated animal model for generalized anxiety disorder (GAD), a severely impairing and difficult-to-treat disease. In this review, we propose contextual conditioning (CC) as an animal model for GAD. We argue that this model has sufficient face validity (there are several symptom similarities), predictive validity (it responds to clinically effective treatments), and construct validity (the underlying mechanisms are comparable). Although the refinement and validation of an animal model is a never-ending process, we want to give a concise
\end{abstract}

L. Luyten $\cdot$ K. van Kuyck $\cdot$ B. Nuttin

Laboratory of Experimental Functional Neurosurgery,

Department of Neurosciences, K.U.Leuven,

Leuven, Belgium

L. Luyten

e-mail: laura.luyten@med.kuleuven.be

K. van Kuyck

e-mail: kris.vankuyck@med.kuleuven.be

D. Vansteenwegen

Centre for the Psychology of Learning and Experimental

Psychopathology, Department of Psychology, K.U.Leuven,

Leuven, Belgium

e-mail: deb.vansteenwegen@psy.kuleuven.be

L. Gabriëls

Psychiatry, UZ Leuven,

Leuven, Belgium

e-mail: loes.gabriels@uzleuven.be

\section{B. Nuttin $(\bowtie)$}

Neurosurgery, UZ Leuven,

Herestraat 49 bus 7003 ,

3000 Leuven, Belgium

e-mail: bart.nuttin@uzleuven.be overview of the currently available evidence. We suggest that the CC model might be a valuable preclinical tool to enhance the development of new treatment strategies and our understanding of GAD.

Keywords Generalized anxiety disorder. Contextual conditioning $\cdot$ Animal model $\cdot$ Face validity $\cdot$ Predictive validity $\cdot$ Construct validity $\cdot$ Rat

To date, the literature on animal models for generalized anxiety disorder (GAD) is very limited. In this review, we briefly describe this psychiatric disorder and put forward an animal model - that is, the contextual conditioning paradigm. Next, we systematically validate this model, based on arguments found in the literature, and discuss three validation criteria: face, predictive, and construct validity. Hence, this review takes a first step toward a valid rat model for GAD. Having an appropriate animal model at one's disposal may trigger future preclinical research to broaden our insight into this impairing disease.

\section{Generalized anxiety disorder}

Anxiety disorders are among the most prevalent psychiatric disorders, with generalized anxiety disorder (as defined in the Diagnostic and Statistical Manual of Mental Disorders, Fourth Edition, Text Revision [DSMIV-TR], 300.02; American Psychiatric Association, 2000) being one of the most common in the primary care setting (Allgulander, 2006). Despite its relatively high prevalence rates (1-year prevalence of about $3 \%$, and lifetime prevalence around 5\%), GAD remains an underdiagnosed and undertreated condition (Narrow, Rae, Robins, \& 
Regier, 2002; Pollack, 2009; Sramek, Zarotsky, \& Cutler, 2002; Varia \& Rauscher, 2002).

GAD is a chronic disease and often shows an erratic course, with worsening of the symptoms during periods of stress. The essential feature of GAD is excessive anxiety or worry (apprehensive expectation), which occurs more days than not for at least 6 months, about a number of events or activities. Characteristic symptoms of GAD are a difficulty controlling the worry, restlessness or feeling keyed up, irritability, difficulty concentrating, muscle tension, sleep disturbance, and being easily fatigued (American Psychiatric Association, 2000). The anxiety, worry, or physical symptoms cause clinically significant distress, and the disabilities and quality of life are comparable to those in major depressive disorder (Wittchen, Carter, Pfister, Montgomery, $\&$ Kessler, 2000). In addition, GAD is a risk factor for the development of many other disorders: either linked disorders, such as depression, or secondary disorders, such as alcohol or benzodiazepine dependence (Tyrer \& Baldwin, 2006).

Selective serotonin reuptake inhibitors, serotoninnorepinephrine reuptake inhibitors, certain tricyclic antidepressants, benzodiazepines, buspirone, and cognitive behavioral therapy (Fricchione, 2004; Hunot, Churchill, Teixeira, \& Silva de Lima, 2007) appear to be effective treatment options for GAD. However, the drugs can have certain side effects and disadvantages, such as sedation, nausea, dizziness, or insufficient treatment of the psychological symptoms. Moreover, the probability of remission of GAD is only $38 \%$ at 5 years, and the probability of relapse among remitters by 3 years is $27 \%$; this suggests that, even among treatment responders, relapses are common (Pollack, Simon, Zalta, Worthington, Hoge, Mick et al., 2006; Snyderman, Rynn, \& Rickels, 2005; Sramek et al., 2002). Thus, although the current standard pharmacotherapies are effective for GAD, especially in the short and medium terms, only a minority of anxious patients experience sustained remission with treatment, and the development of treatment strategies to improve outcome for these treatment-refractory patients remains an area of unmet clinical need (Pollack, 2009; Tyrer \& Baldwin, 2006).

Preclinical research in a valid animal model for GAD can be a first step toward such innovative treatments.

\section{Animal models for GAD}

Numerous anxiety paradigms have been described in the literature: for example, the social interaction test, light-dark exploration, the anxiety/defense test battery, the open field test, the elevated-plus maze, shock-probe burying, fearpotentiated startle after cued fear conditioning, and conflict tests (Graeff \& Zangrossi, 2002; Griebel, 1995; Menard \&
Treit, 1999). In these paradigms, anxiety-like behavior is based on unconditioned (exposure to aversive conditions such as bright light, open areas, high altitudes, or predator odor) or conditioned (pairing of a cue or object with shocks) responses. The applied behavioral measures of anxiety vary and include suppression of normal/expected behavior (such as social interaction, exploration, or drinking when thirsty), duration of shock-probe burying, and increased startle amplitudes.

Although some of the abovementioned models have been suggested as animal models of GAD (light-dark exploration, the anxiety/defense test battery, fearpotentiated startle after cued fear conditioning), they are only partially valid. Systematic examination of the validation criteria in these models is largely lacking in the literature, and although there is often (some) pharmacological similarity between these models and GAD, behavioral or etiological resemblances are mostly absent. One exception might be the elevated T-maze test, which has been proposed as a model of GAD in a systematic review article by Graeff, Netto, and Zangrossi (1998). This maze consists of three arms elevated $50 \mathrm{~cm}$ above the floor. One of the arms is enclosed by lateral walls and is positioned perpendicularly to the two opposed open arms. To be on an open arm seems to be an aversive experience, and inhibitory avoidance, measured as the time taken to leave the enclosed arm, might be related to GAD. On the other hand, elevated mazes primarily produce an innate fear of height and openness (Graeff et al., 1998), and might therefore be of more use in the study of phobic disorders (Bourin, 1997; File, Gonzalez, \& Gallant, 1998). Furthermore, it has been put forward that repeated testing in this model might not produce stable results (Espejo, 1997; File, Zangrossi, Viana, \& Graeff, 1993), ruling out withinsubjects designs and its use as a chronic model.

In our opinion, a good animal model for GAD should sufficiently meet the three validity criteria discussed below (face, predictive, and construct validity). This means, among other things, that the model should display diffuse, unfocused, "generalized" anxiety; be responsive to anxiolytics; and bear some underlying, etiological resemblance with the human disorder. Additionally, it might be interesting to consider chronic protocols (since one hallmark of GAD is its chronicity). However, although this might add surplus value, it is not an essential aspect of a valid animal model. Furthermore, we aimed for a pragmatic model (no lengthy training procedures, the possibility of using within-subjects designs, and working with relatively small groups of animals $[n=7-10])$.

Davis and colleagues (e.g., Davis, 1998) already stated that the chronic state of anxiety resulting from contextual conditioning might be a better model for anxiety, which is free floating, than is cued fear conditioning, which is 
stimulus bound. Furthermore, contextual conditioning has been proposed as a potential animal model for GAD however, to date, without thorough validation (Ameli, Ip, \& Grillon, 2001; Grillon, Baas, Cornwell, \& Johnson, 2006; Santos, Martinez, \& Brandao, 2006; Zanoveli, FerreiraNetto, \& Brandao, 2007). The aim of this review is to make a start toward a systematic validation of contextual conditioning in rats as an animal model for GAD.

\section{Contextual conditioning}

Cued fear conditioning versus contextual conditioning

During a typical Pavlovian fear conditioning experiment, a neutral stimulus - for instance, a tone or light - is repeatedly paired with an aversive stimulus - for instance, a shock. Such a procedure results in conditioned aversive responses to the explicit, initially neutral, stimulus (i.e., cued fear conditioning). Administration of unsignaled shocks will produce conditioned aversive responses to the environmental context - for example, the cage (i.e., contextual conditioning). To a lesser degree, this effect may also be observed in animals conditioned to an explicit cue (Ameli et al., 2001). Conditioning has been demonstrated in both animals and humans. In this review, we will focus on rat conditioning, although sometimes a reference to human conditioning studies will be made.

We share the view of Davis and colleagues, which distinguishes between fear (phasic fear) and anxiety (or sustained fear, as it is sometimes called) (Davis, Walker, \& Lee, 1997; Davis, Walker, Miles, \& Grillon, 2010). Fear is elicited by a specific stimulus (e.g., as in phobias) that has previously been associated with an aversive event, and subsides shortly after the offset of the stimulus. This can be modeled by cued fear conditioning. Anxiety, on the other hand, is elicited by less specific and less predictable threats and lingers on after the threat is removed. Contextual conditioning can model this emotional state.

As stated above, cued fear conditioning is obtained when pairing the explicit cue (e.g., a tone) with a shock (Fig. 1, left). On the other hand, when shocks are given in an unsignaled, unpredictable way, the animals will exhibit long-term, diffuse anxiety symptoms in the experimental context (i.e., the cage) in which the shock was previously administered. This learned response to the cage is referred to as contextual conditioning (Fig. 1, right). The hypervigilance and persistent signs of generalized distress that characterize anxiety may be better modeled by contextual conditioning than by cued fear conditioning (Davis, 1998; Fanselow, 2000; Grillon et al., 2006). In animals and humans, unpredictable aversive stimuli produce incapacitating cognitive, behavioral, and somatic effects (e.g.,

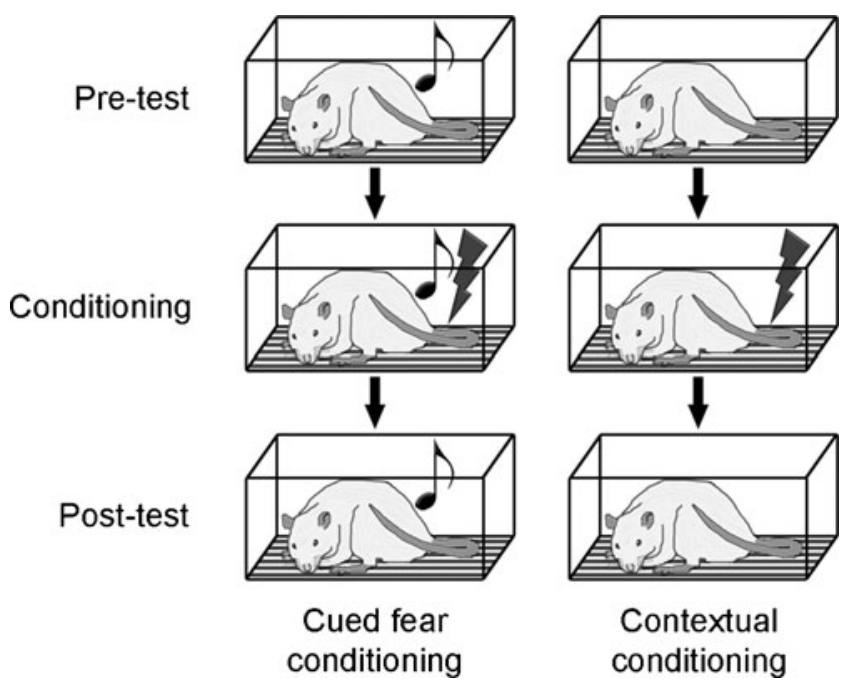

Fig. 1 Basic protocols for cued (left) and contextual (right) conditioning

increased anxiety symptoms, behavioral avoidance) that are not obtained when the aversive stimuli are predictable (Grillon, 2002). Moreover, evidence from developmental, neurobiological, and pharmacological preclinical studies suggests that contextual conditioning and explicit cue conditioning constitute distinct processes mediated by separate brain systems (Ameli et al., 2001; Luyten, Casteels, Vansteenwegen, van Kuyck, Koole, Van Laere et al., 2011). For comprehensive reviews, see Anagnostaras, Gale, and Fanselow (2001); Davis (1998); Gewirtz, McNish, and Davis (2000); Grillon (2002); and Grillon, Lissek, Rabin, McDowell, Dvir and Pine (2008).

\section{Measures of conditioned fear and anxiety}

To assess the conditioned fear or anxiety, a number of specific responses can be quantified. Startle amplitude and freezing are the most common measures in animal protocols.

Startle potentiation is the facilitation of the startle reflex when the subject is in a state of fear or anxiety and is quantified as the increase in startle amplitude (whole-body startle response) to startle stimuli (e.g., a loud noise) delivered during the cue or in the context, as compared to startle stimuli delivered in the absence of the cue or context (Davis, 1986; Lang, Davis, \& Ohman, 2000). An advantage of this measurement is that it is under the control of the experimenters. Startle-evoking stimuli can be presented at any given time during the experiment, functioning as a probe and assessing changes in emotional reactivity to the cue and the context (Grillon, 2002).

An alternative measure that is often used to quantify conditioned fear or anxiety is the time rats spend freezing after exposure to the conditioned cue or after reintroduction 
into the conditioned context (Fendt \& Fanselow, 1999). Freezing is defined as the total absence of movement of the body and whiskers, with the exception of movement necessary for respiration (Fanselow, 1982).

Typically, only one of these measures (startle or freezing) is used. However, the advantages of combining startle and freezing measurements in one protocol are obvious. Two measures provide more information than one about the fear or anxiety state of the rat, and in addition, startle requires motor activity, whereas freezing suppresses movement. We therefore encourage the development of protocols that combine both measures (e.g., Luyten, Vansteenwegen, van Kuyck, Deckers, \& Nuttin, 2011).

\section{Conditioning protocols}

A basic conditioning protocol consists of three consecutive phases, usually carried out on three subsequent days: pretest, training, and post-test (in analogy with Fig. 1). During the pre-test phase, a baseline measurement is obtained, after which the subject is trained (i.e., conditioned to cue or context), and finally the conditioned fear or anxiety is expressed and measured (e.g., Jones, Heldt, Davis, \& Ressler, 2005). The pre-test phase, however, is often omitted and replaced by a comparison of the post-tests between conditioned and control (nonconditioned) groups.

Because of the chronic nature of GAD, the use of a longitudinal experimental design might be an important step in the optimization of an adequate animal model. Accordingly, we propose the development of chronic contextual conditioning protocols with several testing and training days (e.g., Luyten, Vansteenwegen, van Kuyck, \& Nuttin, 2011), following the example of some publications that have described chronic cued fear conditioning protocols (Fendt, 2001; Gewirtz, Falls, \& Davis, 1997; Gewirtz, McNish \& Davis, 1998; Kim \& Davis, 1993). In the meantime, the existing contextual conditioning protocols (with one training phase followed by one post-test) may already constitute a satisfactory animal model of GAD.

In conclusion, as an animal model of GAD, we propose contextual conditioning $(\mathrm{CC})$ in rats, with one or more training and testing sessions, using freezing and/or startle amplitude as measures of anxiety (e.g., Luyten, Vansteenwegen, van Kuyck, Deckers, \& Nuttin, 2011). In what follows, we will give an overview of the arguments supporting this proposition.

\section{Validation of contextual conditioning as an animal model for GAD}

It goes without saying that an animal model of a psychiatric disorder can only model the human disease to a certain extent and will never form a perfect substitute for clinical research. Many cognitive aberrations, for example, cannot be adequately modeled in an animal: most likely, a rat will never worry that a family member will shortly become ill or have an accident, let alone that it would worry about work or finances, while such worry is one of the core features of GAD (Becker, Goodwin, Holting, Hoyer, \& Margraf, 2003). Nevertheless, we agree with the vision of Mineka and Zinbarg (2006) that there are far more advantages than disadvantages in relying on animal research to gain more insight into human disorders, as long as we keep in mind that its basis is "just" a model, which should be validated as thoroughly as possible. The procedure for validating animal models of psychiatric disorders includes consideration of face validity, predictive validity, and construct validity (Willner, 1997).

\section{Face validity}

Face validity refers to the phenomenological similarity between the behavior exhibited by the animal model and the specific symptoms of the human condition. This superficial resemblance in symptomatology between the model and the disorder can be distinguished from construct validity, which relies on similarities in underlying processes or mechanisms (Geyer \& Markou, 1995). There is no reason to suppose that a given condition should manifest itself in identical ways in different species, so a model would not necessarily be invalidated by a lack of correspondence in this area. By the same token, if all of the symptoms do correspond, the model could still be invalid (Willner, 1986).

However, face validity is one of the three criteria (face, predictive, and construct validity) that are generally proposed for assessing animal models of human mental disorders (Willner, 1986). Furthermore, it can provide a starting point for the development of an animal model (Geyer \& Markou, 1995). Therefore, we will give an overview of the symptom (dis)similarities between the CC model and GAD (for a summary, see Table 1).

First of all, the diagnostic criteria for GAD emphasize the persistent excessive anxiety characterizing this disorder and causing clinically significant distress (American Psychiatric Association, 2000). Anxiety is a primitive emotion that is expressed throughout the animal kingdom (Lang, Bradley, \& Cuthbert, 1998; Tyrer, 1999), and rats in the CC model display a range of anxiety symptoms in the conditioned context: a decrease in locomotion is observed, as well as an increase in freezing, urination, ultrasonic vocalizations, defecation, and startle reflex (Antoniadis \& McDonald, 1999).

Anxious patients may present with behavioral inhibition and "mental freezing" (Golbin, Kravitz, \& Keith, 2004; Gorwood, 2004). The muscle tension and inhibition of 
Table 1 Face validity

Generalized anxiety disorder

Symptom
Anxiety symptoms
Muscle tension is a symptom
of GAD (DSM-IV-TR)

Muscle tension, inhibition of motor behavior

Mental freezing, behavioral inhibition

Exaggerated startle is an associated feature of GAD (DSM-IV-TR)

Exaggerated startle

(-) No exaggerated startle

Diarrhoea is an associated feature of GAD (DSM-IV-TR)

$23 \%$ has comorbid irritable bowel syndrome

/

\section{Other key symptoms}

Worrying, difficulty to control the worry (DSM-IV-TR)

Sleep disturbance, being easily fatigued, difficulty concentrating, irritability,... (DSM-IV-TR)

Stress response

(-) No difference of CRF concentrations in cerebrospinal fluid with controls

Elevated ACTH in boys with GAD

Elevated CORT (patients $>60$ years), correlated with GAD severity

Less CORT suppression by dexamethasone in children with GAD

(-) Normal CORT levels

Increased heart rate

(-) Normal heart rate

Higher self-ratings on rapid heartbeat,...

3.1 times greater odds of taking blood pressure medication

Hypertension in late-onset GAD

Increased heart rate and systolic blood pressure in boys with GAD after psychological stress testing

5.9 times more likely to have cardiac disorders

Increased risk of peptic ulcer disease

Increased risk is correlated with the number of anxiety symptoms
Contextual conditioning

Symptom Reference

Startle potentiation

American Psychiatric

Association, 2000

de Beurs et al., 1999; Lyonfields et al., 1995

Golbin et al., 2004;

Gorwood, 2004

American Psychiatric

Association, 2000

Ray et al., 2009

Grillon et al., 2009

American Psychiatric

Association, 2000

Gros et al., 2009;

Lee et al., 2009

I

American Psychiatric Association, 2000

American Psychiatric

Association, 2000

Fossey et al., 1996

Gerra et al., 2000

Mantella et al., 2008

Pfeffer et al., 2007

Hoehn-Saric et al., 1991; Pomara et al., 2005

Thayer et al., 1996

Lyonfields et al., 1995

Hoehn-Saric et al., 2004

Barger \& Sydeman, 2005

Chou, 2009

Gerra et al., 2000

Härter et al., 2003

Goodwin et al., 2009

Goodwin \& Stein, 2002

Freezing

Increased defecation vocalizations to model or assess

?

Role of CRF Elevated CORT and heart rate
Antoniadis \& McDonald, 1999; Phillips \& LeDoux, 1994; etc.

Colonic hypermotility

Increased urination, ultrasonic

Cognitive aspects are difficult

Elevated ACTH

Positive correlation between ACTH and contextual freezing

CORT response is related to shock intensity and degree of behavioral inhibition

Rise in mean arterial pressure
McNish et al., 1997; Santos et al., 2005; etc.

Antoniadis \& McDonald, 1999

Gue et al., 1991; Verleye \& Gillardin, 2004

Antoniadis \& McDonald, 1999
Deak et al., 1999; Hubbard et al., 2007; Ohmura et al., 2008; Pitts et al., 2009

Gray et al., 1993

Tiba et al., 2008

Gray et al., 1993; Sullivan et al., 2004

Cordero et al., 1998
Antoniadis \& McDonald, 1999; Carrive, 2000; Resstel et al., 2008; Resstel et al., 2006

$D S M-I V$-TR Diagnostic and Statistical Manual of Mental Disorders IV (text revision), $C R F$ corticotropin releasing factor, $A C T H$ adrenocorticotropic hormone, CORT corticosterone/cortisol. (-) indicates findings that may contradict or may not directly support the face validity of CC as a GAD model 
motor behavior seen in GAD patients (de Beurs, Beekman, van Balkom, Deeg, van Dyck \& van Tilburg, 1999; Lyonfields, Borkovec, \& Thayer, 1995), as well as the often-experienced feeling of the mind going blank (American Psychiatric Association, 2000), might be analogous to the freezing response of anxious rats (Antoniadis \& McDonald, 1999; Phillips \& LeDoux, 1994).

Additionally, exaggerated startle is a feature associated with GAD, according to the DSM-IV-TR. To our knowledge, two studies have investigated startle in GAD patients. Grillon, Pine, Lissek, Rabin, Bonne and Vythilingam (2009), to their own surprise, could not demonstrate heightened contextual anxiety, as measured by startle, during unpredictable aversive events in GAD patients. They hypothesized that their noxious stimuli might not have been sufficiently aversive. On the other hand, Ray, Molnar, Aikins, Yamasaki, Newman, Castonguay et al. (2009) found that patients showed a greater startle reflex than controls during tasks that induced either worry or relaxation, but not during the baseline period. In agreement with the findings of Ray et al., CC rats display potentiated startle in the conditioned context (McNish, Gewirtz, \& Davis, 1997; Santos, Gargaro, Oliveira, Masson, \& Brandao, 2005). It should be noted that patients suffering from other anxiety disorders with a strong anticipatory anxiety component, such as panic disorder or posttraumatic stress disorder, show elevated conditioned contextual anxiety as measured by startle, but no increase of fearpotentiated startle to a conditioned cue in comparison with healthy controls (Grillon et al., 2008; Grillon et al., 2009).

Furthermore, the DSM-IV-TR included diarrhea as a feature associated with GAD (American Psychiatric Association, 2000), and approximately one-quarter of the GAD patients have comorbid irritable bowel syndrome (Gros, Antony, McCabe, \& Swinson, 2009; Lee, Wu, Ma, Tsang, Guo \& Sung, 2009). Accordingly, CC rats exhibit increased defecation and colonic hypermotility (increased number of colonic spike bursts) in the conditioned context (Antoniadis \& McDonald, 1999; Gue, Junien, \& Bueno, 1991; Verleye \& Gillardin, 2004).

In what follows, some aspects of stress will be discussed. An exaggerated stress response is characteristic of anxiety disorders (Bear, Connors, \& Paradiso, 2001; De Souza, 1995), and it has even been hypothesized that stressinduced changes are a critical step in the pathophysiology of the development of chronic anxiety states (Bear et al., 2001; Shekhar, Truitt, Rainnie, \& Sajdyk, 2005). The sympathetic nervous system and hypothalamo-pituitaryadrenocortical (HPA) axis constitute the primary stress systems (Ulrich-Lai \& Herman, 2009). The HPA axis is activated by stress, which stimulates the hypothalamus to secrete corticotropin-releasing factor. Subsequent increases in circulating adrenocorticotropic hormone secreted by the pituitary gland drive synthesis and secretion of glucocorticoids, such as cortisol, by the adrenal cortex (Herman \& Cullinan, 1997). Finally, the activation of the stress system may result in behavioral (e.g., anxiety) as well as somatic consequences, such as cardiovascular changes, gastric ulceration, and so forth (Chrousos, 2009).

Corticotropin-releasing factor (CRF) is a principal mediator of the stress response and modulates diverse neurotransmitter systems (including glutamate, dopamine, serotonin, and norepinephrine) that are implicated in affective and anxiety responses (Risbrough \& Stein, 2006).

Surprisingly, a study of CRF concentrations in cerebrospinal fluid with a small number of subjects could not find a difference between GAD patients and controls (Fossey, Lydiard, Ballenger, Laraia, Bissette \& Nemeroff, 1996). However, the stressful sampling technique (lumbar puncture) might have masked a difference (Risbrough \& Stein, 2006).

On the other hand, several studies provide evidence for a role of CRF in contextual conditioning (Deak, Nguyen, Ehrlich, Watkins, Spencer, Maier et al., 1999; Hubbard, Nakashima, Lee, \& Takahashi, 2007; Ohmura, Yamaguchi, Izumi, Matsumoto, \& Yoshioka, 2008; Pitts, Todorovic, Blank, \& Takahashi, 2009). To clarify this apparent discrepancy between GAD and CC, further CRF studies in patients are needed.

Adrenocorticotropic hormone (ACTH) has been investigated to some extent in GAD patients and in the CC model.

A study investigating 12-year-old boys with GAD showed significantly higher plasma values of ACTH in anxious subjects than in controls. After a psychologically stressful test, no significant changes were found in anxious subjects and controls. Consequently, it was hypothesized that the baseline data probably did not represent the basal condition, but might be induced by anticipation stress for the test, or might even mirror persistent hyperactivity of the stress response system (Gerra, Zaimovic, Zambelli, Timpano, Reali, Bernasconi et al., 2000).

A study in rats showed significantly higher plasma ACTH levels after reexposure to a conditioned context, as compared with nonshocked controls (Gray, Piechowski, Yracheta, Rittenhouse, Bethea \& Van de Kar, 1993). Another study found a positive correlation between ACTH plasma levels and contextual freezing (Tiba, Oliveira, Rossi, Tufik, \& Suchecki, 2008).

Corticosterone (CORT) is the rat analogue of the human hormone cortisol (also CORT) (Ron \& Robbins, 2003). These glucocorticoids serve to alert the organism to environmental or physiological changes and to defend homeostasis (Herman \& Cullinan, 1997).

The findings concerning this hormone in both GAD patients and $\mathrm{CC}$ rats are not univocal. Some studies in humans have found no differences in CORT levels between 
GAD patients and nonanxious controls (Hoehn-Saric, McLeod, Lee, \& Zimmerli, 1991; Pomara, Willoughby, Sidtis, Cooper, \& Greenblatt, 2005). Others, however, have found differences: children with GAD showed significantly less CORT suppression by dexamethasone than did healthy children, suggesting HPA-axis hyperactivity among children with this diagnosis (Pfeffer, Altemus, Heo, \& Jiang, 2007). Furthermore, GAD subjects over 60 years of age had elevated basal salivary CORT levels and higher peak CORT levels, as compared to nonanxious controls. Additionally, the severity of GAD was positively correlated with CORT levels (Mantella, Butters, Amico, Mazumdar, Rollman, Begley et al., 2008).

Two studies have reported increased CORT levels when rats were reexposed to a conditioned context (Gray et al., 1993; Sullivan, Apergis, Bush, Johnson, Hou \& Ledoux, 2004). In addition, others showed that this CORT response was related to both stressor intensity $(0.2,0.4$, or $1 \mathrm{~mA})$ at training and the behavioral inhibition displayed at testing. Thus, the more intense the stressor, the greater the rat's future reaction, at both the behavioral and neuroendocrine levels, if reexposed to the conditioned context (Cordero, Merino, \& Sandi, 1998).

GAD patients may present with cardiovascular changes. Some studies have found that patients with GAD showed an increased heart rate, while others indicated that patients had a normal heart rate (Lyonfields et al., 1995; Thayer, Friedman, \& Borkovec, 1996). However, subjective ratings of rapid heartbeat, sweating, difficulty breathing, and feeling tense are higher in patients than in healthy controls (Hoehn-Saric, McLeod, Funderburk, \& Kowalski, 2004). A cross-sectional study found that patients with GAD have 3.1 times greater odds of taking blood pressure medication (Barger \& Sydeman, 2005). Another study noticed that lateonset GAD ( $\geq 50$ years) is more likely to be associated with the presence of hypertension than is early-onset GAD (Chou, 2009). Furthermore, in contrast to controls, heart rate and systolic blood pressure increased significantly in boys with GAD after psychological stress testing (Gerra et al., 2000). Finally, patients with panic or GAD are 5.9 times more likely than controls to have cardiac disorders (angina, myocardial infarction, mitral valve prolapse), even after adjusting for comorbid depression, substance abuse, and gender (Härter, Conway, \& Merikangas, 2003).

Conditioned anxiety evoked by reexposure to the footshock chamber after conditioning is associated with cardiovascular changes: a marked rise in mean arterial blood pressure $(+35 \mathrm{~mm} \mathrm{Hg}$ above a resting baseline of $105 \mathrm{~mm} \mathrm{Hg}$ ) and an increased heart rate. Although these cardiovascular changes are also seen with conditioned fear to a discrete stimulus, the effects last longer after contextual conditioning (Antoniadis \& McDonald, 1999; Carrive, 2000; Resstel, Alves, Reis, Crestani, Correa \&
Guimaraes, 2008; Resstel, Joca, Moreira, Correa, \& Guimaraes, 2006).

GAD is associated with a significantly increased risk of peptic ulcer disease, even after adjusting for demographics, other mood and anxiety disorders, any personality disorder, nicotine dependence, and alcohol dependence (Goodwin, Keyes, Stein, \& Talley, 2009). Moreover, a dose-response relationship exists between the number of anxiety symptoms and the increased risk of peptic ulcer disease (Goodwin \& Stein, 2002).

In a study comparing predictable and unpredictable shocks, none of the rats receiving predictable shocks showed any ulcers, while $75 \%$ of the rats receiving unpredictable shocks formed ulcers (Seligman, 1968). Another study compared unsignaled shocks given at fixed-time or variable-time (a truly unpredictable protocol) intervals. After exposure to the shocks, both groups showed gastric ulceration, but there were significantly more ulcers in the variable-time-scheduled rats, indicating an even more subtle effect of predictability (Guile, 1987).

We can conclude that there is considerable similarity between rats in the CC model and GAD patients. Therefore, in our opinion, the $\mathrm{CC}$ model has sufficient face validity.

\section{Predictive validity}

A model has predictive validity if it successfully discriminates between effective and ineffective treatments (Willner, 1986).

Table 2 gives an overview of the compounds that have been tested in GAD patients and in the animal model. Studies have been conducted on a wide range of antidepressants, benzodiazepines, serotonin-1A receptor antagonists, and a whole series of other drugs. All CC studies were carried out using rats, unless stated otherwise. The protocols used to obtain the $\mathrm{CC}$ model are variable, with different measures of anxiety (freezing or startle), which is typical for this kind of research. This overview gives a first and global impression of the predictive validity of the model. However, the overview has several limitations: for instance, no distinction was made between acute and chronic treatments. Furthermore, we only included published results, which implies a bias against negative results. Therefore, our summary of the ineffective treatments is probably incomplete. Finally, articles on GAD published before 1995 employed the DSM-III criteria for GAD (minimum duration of 1 month) instead of the current DSM-IV-TR criteria (minimum duration of disease is 6 months). However, the majority of these studies used severely affected patients, with a disease duration longer than 1 month.

Antidepressants are often used as a first-line treatment for GAD, and a wide range of these drugs have been tested. They generally offer a good choice of therapy in GAD, 


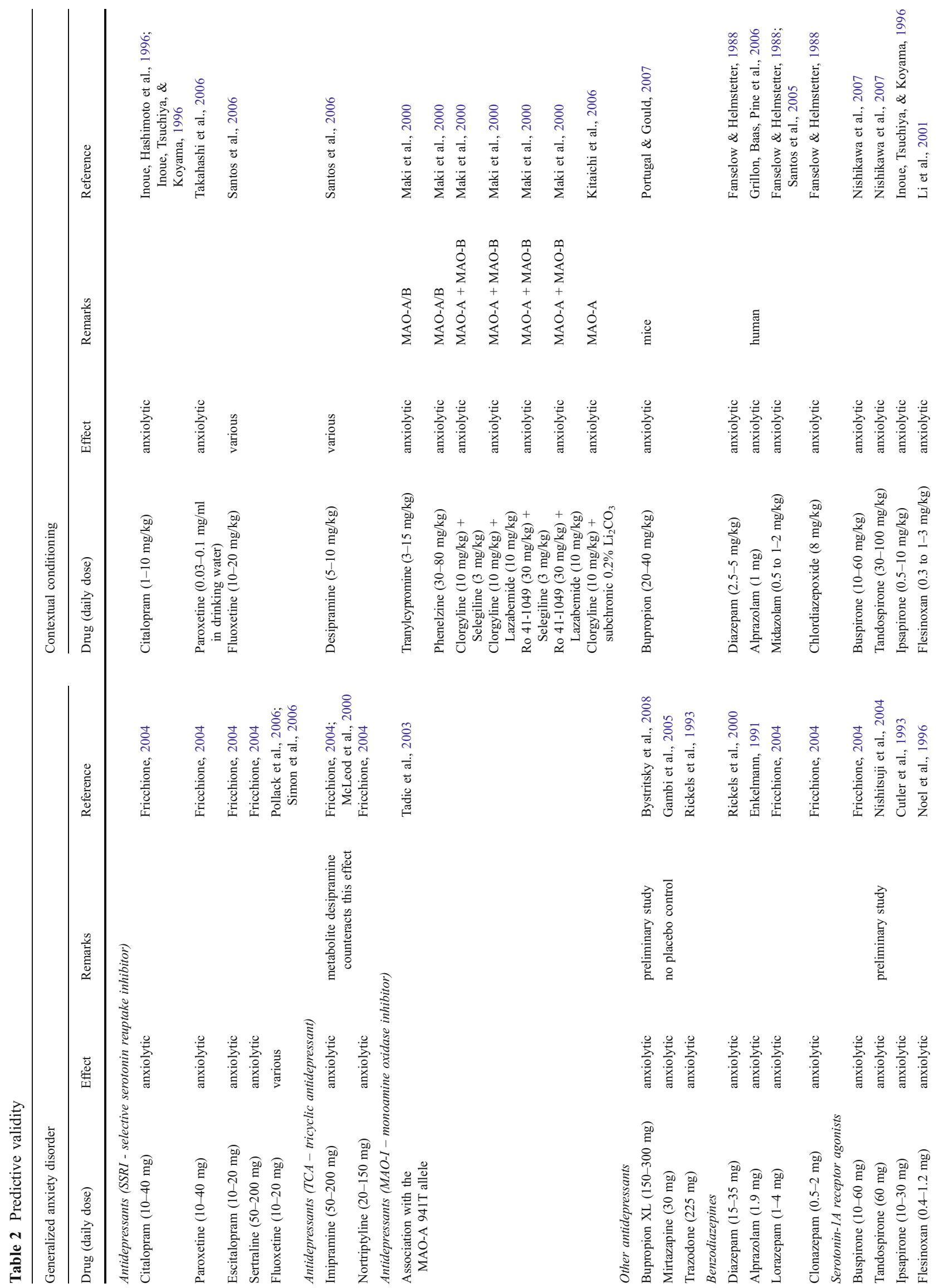


especially when it comes to treating not only the anxiety, but also the depressive symptoms that are often comorbid with chronic anxiety. Several selective serotonin reuptake inhibitors (SSRIs) are effective in both GAD (Fricchione, 2004; Kapczinski, Lima, Souza, \& Schmitt, 2003) and CC (Inoue, Hashimoto, Tsuchiya, Izumi, Ohmori \& Koyama, 1996; Inoue, Tsuchiya, \& Koyama, 1996; Takahashi, Morinobu, Iwamoto \& Yamawaki, 2006). However, this is not true for all SSRIs; for instance, fluoxetine produces inconsistent results in GAD, which might be partially explained by age of onset and gender (Pollack et al., 2006; Simon, Zalta, Worthington, Hoge, Christian, Stevens et al., 2006), and also in the CC model, where the effects depend on the shock intensity used for conditioning (Santos et al., 2006). Tricyclic antidepressents (TCAs) such as imipramine and nortriptyline are effective in GAD (Fricchione, 2004). Remarkably, the positive effects of imipramine are counteracted by its metabolite desipramine (the higher the plasma level of desipramine, the smaller the reduction in anxiety levels; McLeod, Hoehn-Saric, Porges, Kowalski, \& Clark, 2000). This is in line with the varying effects of desipramine in the CC model (Santos et al., 2006). To our knowledge, no other TCAs have been tested in the animal model. Serotonin-norepinephrine reuptake inhibitors are anxiolytic in GAD (duloxetine, venlafaxine; Fricchione, 2004; Rynn, Russell, Erickson, Detke, Ball, Dinkel et al., 2008), but have not been examined in the rat model. Monoamine oxidase (MAO) inhibitors have not been clinically tested in GAD, although a gene allele association study did provide evidence for an association between the MAO-A 941T allele and GAD (Tadic, Rujescu, Szegedi, Giegling, Singer, Möller \& Dahmen, 2003). Several MAO inhibitors have been used in the CC model and suggest that acute inhibition of both MAO-A and MAO-B reduces anxiety, whereas inhibition of either MAO-A or MAO-B alone fails to elicit this anxiolytic effect. The effective drugs used in this study were tranylcypromine, phenelzine, clorgyline + selegiline, clorgyline + lazabemide, Ro 41-1049 + selegiline, and Ro 411049 + lazabemide (Maki, Inoue, Izumi, Muraki, Ito, Kitaichi et al., 2000). Another study described the anxiolytic effects of clorgyline following subchronic $0.2 \%$ $\mathrm{Li}_{2} \mathrm{CO}_{3}$ (Kitaichi, Inoue, Nakagawa, Izumi, \& Koyama, 2006). Other antidepressants, such as bupropion XL (norepinephrine and dopamine reuptake inhibitor, as well as nicotinic antagonist), mirtazapine (noradrenergic and specific serotonergic antidepressant), and trazodone (serotonin-2/1C receptor antagonist), are effective in the treatment of GAD (Bystritsky, Kerwin, Feusner, \& Vapnik, 2008; Gambi, De Berardis, Campanella, Carano, Sepede, Salini et al., 2005; Rickels, Downing, Schweizer, \& Hassman, 1993). Accordingly, bupropion has anxiolytic effects in the CC model (Portugal \& Gould, 2007). 
Benzodiazepines are very valuable anxiolytics and have long been used to treat anxiety. They are still particularly appropriate as short-term treatments, but should be used with caution, because of their risk for abuse and dependency. Treatment with a variety of benzodiazepines has been found to be effective in GAD (diazepam, alprazolam, lorazepam, clonazepam; Enkelmann, 1991; Fricchione, 2004; Rickels, DeMartinis, \& Aufdembrinke, 2000), as well as in the CC model (diazepam, alprazolam, midazolam, chlordiazepoxide; Fanselow \& Helmstetter, 1988; Grillon, Baas, Pine et al., 2006; Santos et al., 2005).

A newer class of anxiolytics, the serotonin-1A receptor agonists, shows a similar therapeutic profile. These drugs (buspirone, tandospirone, ipsapirone, and flesinoxan) are effective in both GAD and CC (Chessick, Allen, Thase, Batista Miralha da Cunha, Kapczinski, de Lima et al., 2006; Cutler, Sramek, Keppel Hesselink, Krol, Roeschen, Rickels et al., 1993; Fricchione, 2004; Inoue et al., 1996; Li, Inoue, Hashimoto, \& Koyama, 2001; Nishikawa, Inoue, Masui, Izumi, \& Koyama, 2007; Nishitsuji, To, Murakami, Kodama, Kobayashi, Yamada et al., 2004; Noel, Stevens, \& Bradford, 1996).

Beta-blockers such as propranolol are useful in GAD patients because of their effects on somatic aspects of anxiety such as tremor and cardiovascular symptoms (Dubovsky, 1990; Milanov, 2007). In the CC model, propranolol has produced varying results (Grillon, Cordova, Morgan, Charney, \& Davis, 2004), which might be explained by the fact that propranolol is not really an anxiolytic, but rather an antitremor drug.

The antihistamine hydroxyzine is anxiolytic in GAD patients (Llorca et al., 2002), but has not yet been tested in the $\mathrm{CC}$ model.

Randomized controlled trials have shown that anticonvulsants (valproate, pregabalin) are effective anxiolytics in GAD patients (Aliyev \& Aliyev, 2008; Mula, Pini, \& Cassano, 2007). To our knowledge, they have not yet been tested in the CC model, but a cued fear conditioning study found that valproate enhances extinction, but also enhances renewal of the original conditioned fear, which makes it difficult to draw a straightforward conclusion about a potential anxiolytic effect (Bredy \& Barad, 2008).

Antipsychotics such as flupentixol and trifluoperazine are effective in the treatment of GAD patients (Bjerrum, Allerup, Thunedborg, Jakobsen, \& Bech, 1992; Mendels, Krajewski, Huffer, Taylor, Secunda, Schless et al., 1986). This class of drugs has not yet been tested in the CC model, but infusion of flupentixol in the medial prefrontal cortex decreased fear in one cued fear conditioning experiment (Pezze, Bast, \& Feldon, 2003).

Although they are not (yet) part of the standard treatment of GAD, several metabotropic glutamate receptor ( $m G l u R$ ) agents have been investigated. LY354740, a mGluR2/3 agonist, is anxiolytic in GAD (Michelson, Levine, Dellva, Mesters, Schoepp, Dunayevich et al., 2005), as well as in the CC model (Grillon, Cordova, Levine, \& Morgan, 2003). LY544344, a precursor of LY354740, is also effective in GAD (Dunayevich, Erickson, Levine, Landbloom, Schoepp \& Tollefson, 2008). Another mGluR2 agonist, 4aminopyrrolidine-2,4-dicarboxylic acid (APDC) has anxiolytic effects in the animal model (Riedel, Harrington, Kozikowski, Sandager-Nielsen, \& Macphail, 2002). The mGluR1 antagonist 1-aminoindan-1,5-dicarboxylic acid (AIDA) produces anxiolytic effects in the CC model (Christoffersen, Christensen, Harrington, Macphail, \& Riedel, 1999), but has not yet been tested in GAD patients.

A few studies have indicated a role for cholecystokinin (CCK) in anxiety, and viewed from that perspective, the role of CCK receptor agents as potential anxiolytics has been investigated. The CCK-B antagonist, CI-988, was not anxiolytic in GAD, but the authors pointed out that the oral bioavailability of CI-988 is very low and that the conclusions in the three participating centers varied (Adams, Pyke, Costa, Cutler, Schweizer, Wilcox et al., 1995). On the other hand, the CCK-B agonist pentagastrin was anxiogenic in GAD patients (Brawman-Mintzer, Lydiard, Bradwejn, Villarreal, Knapp, Emmanuel et al., 1997), which seems to be in line with the effect of a CCK-B antagonist (LY288513) in the animal model, assuming that agonists and antagonists have opposite effects. LY288513 and CCK-A antagonist lorglumide are both anxiolytic in the $\mathrm{CC}$ model, in contrast to the CCK-A/B antagonist loxiglumide (Izumi, Inoue, Tsuchiya, Hashimoto, Ohmori \& Koyama, 1996).

In summary, the model responds to a wide range of clinically effective treatments, and there are very few false positives or negatives. We can therefore conclude that the model has satisfactory predictive validity.

\section{Construct validity}

An animal model has construct validity if it is based on a robust theoretical rationale (Willner, 1986). Although face validity depends on superficial resemblance, construct validity refers to similarities in underlying mechanisms or etiology (Geyer \& Markou, 1995). The limited insight into the mechanisms of GAD is obviously a serious drawback for the assessment of this type of validity; however, this is the case in animal models for most psychiatric disorders. In this section, we will give an overview of the etiological hypotheses and existing theories on underlying mechanisms for GAD and make an attempt to link them to the animal model.

\section{Etiological hypotheses}

The heritability of GAD is estimated at about $20 \%$, but the genes involved have not been identified thus far (Hettema, 
Prescott, \& Kendler, 2001; Mackintosh, Gatz, Wetherell, \& Pedersen, 2006; Stein, 2009). Thus, at this moment, the genetic approach is not useful to validate this animal model. The majority of the variance in GAD is related to individual specific environmental factors (Hettema et al., 2001; Mackintosh et al., 2006).

It has been proposed that uncontrollable and unpredictable aversive events may play an important role in the development of GAD (Mineka \& Zinbarg, 2006). Roemer et al. explored this etiological hypothesis and found that GAD patients were more likely than nonanxious controls to report exposure to a stressful life event (Roemer, Molina, Litz, \& Borkovec, 1996). In the CC model, the rat is exposed to uncontrollable and unpredictable events (electric shocks) in the conditioning phase, leading to the expression of anxiety during the post-test. It is evident that not all environmental factors that might increase the risk to develop GAD (separation during childhood, role inversion during childhood, lack of social interactions, etc.; Gosselin \& Laberge, 2003) are represented in the CC model.

Another approach to evaluate construct validity is to investigate the associated neurocircuitry (Willner \& Mitchell, 2002). Although there is no decisive conclusion about the circuitry of GAD (Cannistraro \& Rauch, 2003), numerous brain regions have been implicated in this disease, including, for instance, the amygdala, anterior cingulate cortex, hippocampus, and prefrontal cortex (De Bellis, Keshavan, Shifflett, Iyengar, Dahl, Axelson et al., 2002; Mathew, Mao, Coplan, Smith, Sackeim, Gorman et al., 2004; Mathew, Price, Mao, Smith, Coplan, Charney et al., 2008; Paulesu, Sambugaro, Torti, Danelli, Ferri, Scialfa et al., 2010; Wu, Buchsbaum, Hershey, Hazlett, Sicotte \& Johnson, 1991). The first three of these brain regions appear to be involved in contextual conditioning as well (Alvarez, Biggs, Chen, Pine, \& Grillon, 2008; Anagnostaras et al., 2001; Walker, Toufexis, \& Davis, 2003). It is beyond the scope of this review to give a comprehensive overview of all brain regions implicated in GAD and/or the CC model.

\section{Theories of underlying mechanisms}

Intolerance of uncertainty, defined as "the tendency to react negatively on an emotional, cognitive, and behavioral level to uncertain situations and events," has been shown to be a central mechanism involved in GAD (Dugas, Buhr, \& Ladouceur, 2004; Dugas, Gagnon, Ladouceur, \& Freeston, 1998). Although intolerance of uncertainty is probably most related to GAD, it may also be relevant to obsessivecompulsive disorder (OCD), and particularly to doubting and checking compulsions (Holaway, Heimberg, \& Coles, 2006). This finding is not surprising, given the partial overlap between OCD and GAD (Nutt \& Malizia, 2006). Anyhow, the marked intolerance of uncertainty in GAD patients is in line with the observations in the $\mathrm{CC}$ model. As already mentioned, unpredictable shocks produce more anxiety, along with its accompanying cognitive, behavioral, and somatic effects, than do controllable and predictable aversive events (Grillon, 2002; Mineka \& Kihlstrom, 1978). One could say that the rats in the CC model might be "uncertain" about the administration of shocks and that this uncertainty is harder to tolerate than the certainty of signaled shocks.

Another factor that might contribute to the maintenance of GAD is the so-called fear of anxiety, also known as anticipation anxiety, that is seen in patients (Turk, Heimberg, Luterek, Mennin, \& Fresco, 2005). Buhr and Dugas (2009) showed that subjects with experimentally elevated fear of anxiety showed higher levels of worry than did subjects whose fear of anxiety was reduced. Moreover, increased fear of anxiety in combination with intolerance of uncertainty produced even higher levels of worry. However, fear of anxiety is a cognitive concept, and therefore it is very difficult or even impossible to translate this to the animal model.

This remark applies to other theoretical models of generalized anxiety disorder, as well (e.g., the avoidance model of worry, the metacognitive model; for an overview, see Behar, DiMarco, Hekler, Mohlman, \& Staples, 2009). These theories primarily focus on the worry aspect of GAD, which is, together with excessive anxiety, a core feature of the disease. However, these cognitive aspects are probably typically human. Eventually, in all animal models for psychiatric disorders, the limits of what can be modeled in a rat are reached. Nevertheless, valuable information can be obtained, even from an "imperfect" animal model.

Next, it has been argued that patients with GAD are characterized by an absence of experienced safety signals, and thus engage in persistent searches for safety. However, they rarely attain (long-lasting) safety and, as a consequence, remain alert and tense. Accordingly, it has been suggested that learning-based psychotherapy should not merely rely on the deconditioning of danger signals, but should also address the learning about safety signals (Woody \& Rachman, 1994). When a rat in the CC model is exposed to unpredictable shocks during the conditioning phase, there are virtually no safety signals. On the other hand, a rat in the $\mathrm{CC}$ model can also be trained using explicitly unpaired cue (e.g., tone) and shock presentations. Rescorla stated that the cue then provides information that the shock will not occur, and as a consequence, this cue becomes a safety signal or conditioned inhibitor (Rescorla, 1969). Thus, theoretically, the rats can learn that the presence of the tone predicts the absence of the shock and will subsequently treat the tone as a safety signal (Gleitman \& Landau, 1994). However, in practice, safety signals are acquired more slowly than danger signals or are not 
established at all (Candido, Gonzalez, \& de Brugada, 2004; Marschner, Kalisch, Vervliet, Vansteenwegen, \& Buchel, 2008; Orman \& Stewart, 2007). Thus, the rat cannot identify a safety signal, and as a consequence, it is constantly anxious in the conditioned context. This is in line with the observation of insufficient safety signals in GAD patients. Additionally, some authors suggest that, as its search for safety fails, the rat finally may display behavior resembling hopelessness and depression, a phenomenon referred to as learned helplessness (Maier \& Seligman, 1976; Woody \& Rachman, 1994). Since its discovery, learned helplessness has proven a valuable animal model of depression (Willner, 1986). In accordance, more than half of the GAD patients also suffer from major depression (Kessler, DuPont, Berglund, \& Wittchen, 1999). Furthermore, it has been described that learned helplessness entails cognitive deficits (e.g., associative learning difficulties, impaired problem solving capacities), which are very similar to what is seen in GAD patients (memory and attention deficits, inability to solve relatively simple problems; Dugas et al., 2004; Maier \& Seligman, 1976; Stein, 2009). However, note that the learned helplessness paradigm uses operant conditioning in which performance deficits (e.g., pressing a lever, crossing a barrier) are measured, whereas the $\mathrm{CC}$ model is a classical conditioning paradigm. In addition, uncontrollability plays an important role in learned helplessness, resulting in a motivational deficit, whereas in the CC model, the key feature is unpredictability, producing anxious apprehension (Mineka \& Hendersen, 1985; Willner, 1986). Although some might regard the close connection with the learned helplessness paradigm as a shortcoming for the specificity and validity of the CC model as an animal model for GAD, in our opinion, it is an asset rather than a weakness, because of the evident relationship between GAD and major depression.

In summary, some mechanisms of GAD bear a resemblance to those of contextual conditioning. Thus, there are indications that the $\mathrm{CC}$ model has construct validity.

\section{Conclusion}

In our opinion, there are substantial arguments to consider the CC model as an animal model for GAD. There is superficial resemblance in symptomatology (face validity), the model responds to a wide range of clinically effective treatments (predictive validity), and there are reasons to believe that there are similarities in etiology and underlying mechanisms, as well (construct validity). However, we do not want to claim that the $\mathrm{CC}$ model is the only appropriate model for GAD, nor that the $\mathrm{CC}$ paradigm solely models GAD (cf. the link with learned helplessness and the chronic anxiety component in other [anxiety] disorders). Nevertheless, we think that there is sufficient evidence to use the $\mathrm{CC}$ model for preclinical GAD studies. It is our hope that research in an appropriate animal model will lead to a better understanding and treatment of this severe psychiatric disorder.

Disclosure The authors declare that, except for income received from the primary employer, no financial support or compensation has been received from any individual or corporate entity over the past 3 years for research or professional service, and no personal financial holdings could be perceived as constituting a potential conflict of interest.

\section{References}

Adams, J. B., Pyke, R. E., Costa, J., Cutler, N. R., Schweizer, E., Wilcox, C. S., et al. (1995). A double-blind, placebo-controlled study of a CCK-B receptor antagonist, CI-988, in patients with generalized anxiety disorder. Journal of Clinical Psychopharmacology, 15, 428-434.

Aliyev, N. A., \& Aliyev, Z. N. (2008). Valproate (depakine-chrono) in the acute treatment of outpatients with generalized anxiety disorder without psychiatric comorbidity: randomized, doubleblind placebo-controlled study. European Psychiatry, 23, 109114.

Allgulander, C. (2006). Generalized anxiety disorder: what are we missing? European Neuropsychopharmacology, 16(Suppl. 2), S101-S108.

Alvarez, R. P., Biggs, A., Chen, G., Pine, D. S., \& Grillon, C. (2008). Contextual fear conditioning in humans: cortical-hippocampal and amygdala contributions. The Journal of Neuroscience, 28, 6211-6219.

Ameli, R., Ip, C., \& Grillon, C. (2001). Contextual fear-potentiated startle conditioning in humans: replication and extension. Psychophysiology, 38, 383-390.

American Psychiatric Association. (2000). Diagnostic and statistical manual of mental disorders: DSM-IV-TR (4th ed.). Washington, DC: American Psychiatric Association.

Anagnostaras, S. G., Gale, G. D., \& Fanselow, M. S. (2001). Hippocampus and contextual fear conditioning: recent controversies and advances. Hippocampus, 11, 8-17.

Antoniadis, E. A., \& McDonald, R. J. (1999). Discriminative fear conditioning to context expressed by multiple measures of fear in the rat. Behavioural Brain Research, 101, 1-13.

Barger, S. D., \& Sydeman, S. J. (2005). Does generalized anxiety disorder predict coronary heart disease risk factors independently of major depressive disorder? Journal of Affective Disorders, 88 , 87-91.

Bear, M. F., Connors, B. W., \& Paradiso, M. A. (2001). Neuroscience: exploring the brain (2nd ed.). Baltimore, MD: Lippincott Williams \& Wilkins.

Becker, E. S., Goodwin, R., Holting, C., Hoyer, J., \& Margraf, J. (2003). Content of worry in the community: what do people with generalized anxiety disorder or other disorders worry about? Journal of Nervous Mental Disorders, 191, 688-691.

Behar, E., DiMarco, I. D., Hekler, E. B., Mohlman, J., \& Staples, A. M. (2009). Current theoretical models of generalized anxiety disorder (GAD): conceptual review and treatment implications. Journal of Anxiety Disorders, 23, 1011-1023. 
Bjerrum, H., Allerup, P., Thunedborg, K., Jakobsen, K., \& Bech, P. (1992). Treatment of generalized anxiety disorder: comparison of a new beta-blocking drug (CGP $361 \mathrm{~A}$ ), low-dose neuroleptic (flupenthixol), and placebo. Pharmacopsychiatry, 25, 229-232.

Bourin, M. (1997). Animal models of anxiety: are they suitable for predicting drug action in humans? Polish Journal of Pharmacology, 49, 79-84.

Brawman-Mintzer, O., Lydiard, R. B., Bradwejn, J., Villarreal, G., Knapp, R., Emmanuel, N., et al. (1997). Effects of the cholecystokinin agonist pentagastrin in patients with generalized anxiety disorder. The American Journal of Psychiatry, 154, 700702.

Bredy, T. W., \& Barad, M. (2008). The histone deacetylase inhibitor valproic acid enhances acquisition, extinction, and reconsolidation of conditioned fear. Learning \& Memory, 15, 39-45.

Buhr, K., \& Dugas, M. J. (2009). The role of fear of anxiety and intolerance of uncertainty in worry: an experimental manipulation. Behaviour Research and Therapy, 47, 215-223.

Bystritsky, A., Kerwin, L., Feusner, J. D., \& Vapnik, T. (2008). A pilot controlled trial of bupropion XL versus escitalopram in generalized anxiety disorder. Psychopharmacology Bulletin, $41,46-51$.

Candido, A., Gonzalez, F., \& de Brugada, I. (2004). Safety signals from avoidance learning but not from yoked classical conditioning training pass both summation and retardation tests for inhibition. Behavioral Processes, 66, 153-160.

Cannistraro, P. A., \& Rauch, S. L. (2003). Neural circuitry of anxiety: evidence from structural and functional neuroimaging studies. Psychopharmacology Bulletin, 37, 8-25.

Carrive, P. (2000). Conditioned fear to environmental context: Cardiovascular and behavioral components in the rat. Brain Research, 858, 440-445.

Chessick, C. A., Allen, M. H., Thase, M., Batista Miralha da Cunha, A. B., Kapczinski, F. F., de Lima, M. S., et al. (2006). Azapirones for generalized anxiety disorder. Cochrane Database of Systematic Reviews, CD006115.

Chou, K. L. (2009). Age at onset of generalized anxiety disorder in older adults. The American Journal of Geriatric Psychiatry, 17, 455-464.

Christoffersen, G. R., Christensen, L. H., Harrington, N. R., Macphail, E. M., \& Riedel, G. (1999). Task-specific enhancement of shortterm, but not long-term, memory by class I metabotropic glutamate receptor antagonist 1-aminoindan-1, 5-dicarboxylic acid in rats. Behavioural Brain Research, 101, 215-226.

Chrousos, G. P. (2009). Stress and disorders of the stress system. Nature Reviews Endocrinology, 5, 374-381.

Cordero, M. I., Merino, J. J., \& Sandi, C. (1998). Correlational relationship between shock intensity and corticosterone secretion on the establishment and subsequent expression of contextual fear conditioning. Behavioral Neuroscience, 112, 885-891.

Cutler, N. R., Sramek, J. J., Keppel Hesselink, J. M., Krol, A., Roeschen, J., Rickels, K., et al. (1993). A double-blind, placebocontrolled study comparing the efficacy and safety of ipsapirone versus lorazepam in patients with generalized anxiety disorder: a prospective multicenter trial. Journal of Clinical Psychopharmacology, 13, 429-437.

Davis, M. (1986). Pharmacological and anatomical analysis of fear conditioning using the fear-potentiated startle paradigm. Behavioral Neuroscience, 100, 814-824.

Davis, M. (1998). Are different parts of the extended amygdala involved in fear versus anxiety? Biological Psychiatry, 44, 12391247.

Davis, M., Walker, D. L., \& Lee, Y. (1997). Amygdala and bed nucleus of the stria terminalis: differential roles in fear and anxiety measured with the acoustic startle reflex. Philosophical Transactions of the Royal Society B, 352, 1675-1687.
Davis, M., Walker, D. L., Miles, L., \& Grillon, C. (2010). Phasic vs. sustained fear in rats and humans: role of the extended amygdala in fear vs. anxiety. Neuropsychopharmacology, 35, $105-135$.

De Bellis, M. D., Keshavan, M. S., Shifflett, H., Iyengar, S., Dahl, R. E., Axelson, D. A., et al. (2002). Superior temporal gyrus volumes in pediatric generalized anxiety disorder. Biological Psychiatry, 51, 553-562.

de Beurs, E., Beekman, A. T., van Balkom, A. J., Deeg, D. J., van Dyck, R., \& van Tilburg, W. (1999). Consequences of anxiety in older persons: its effect on disability, well-being and use of health services. Psychological Medicine, 29, 583-593.

De Souza, E. B. (1995). Corticotropin-releasing factor receptors: physiology, pharmacology, biochemistry and role in central nervous system and immune disorders. Psychoneuroendocrinology, 20, 789-819.

Deak, T., Nguyen, K. T., Ehrlich, A. L., Watkins, L. R., Spencer, R. L., Maier, S. F., et al. (1999). The impact of the nonpeptide corticotropin-releasing hormone antagonist antalarmin on behavioral and endocrine responses to stress. Endocrinology, 140, 79 86.

Dubovsky, S. L. (1990). Generalized anxiety disorder: new concepts and psychopharmacologic therapies. The Journal of Clinical Psychiatry, 51(Suppl), 3-10.

Dugas, M. J., Buhr, K., \& Ladouceur, R. (2004). The role of intolerance of uncertainty. In R. G. Heimberg, C. L. Turk, \& D. S. Mennin (Eds.), Generalized anxiety disorder: advances in research and practice. New York: Guilford Press. pp. 143-163.

Dugas, M. J., Gagnon, F., Ladouceur, R., \& Freeston, M. H. (1998). Generalized anxiety disorder: a preliminary test of a conceptual model. Behaviour Research and Therapy, 36, 215-226.

Dunayevich, E., Erickson, J., Levine, L., Landbloom, R., Schoepp, D. D., \& Tollefson, G. D. (2008). Efficacy and tolerability of an mGlu2/3 agonist in the treatment of generalized anxiety disorder. Neuropsychopharmacology, 33, 1603-1610.

Enkelmann, R. (1991). Alprazolam versus buspirone in the treatment of outpatients with generalized anxiety disorder. Psychopharmacology, 105, 428-432.

Espejo, E. F. (1997). Effects of weekly or daily exposure to the elevated plus-maze in male mice. Behavioural Brain Research, $87,233-238$.

Fanselow, M. S. (1982). The postshock activity burst. Animal Learning \& Behavior, 10, 448-454.

Fanselow, M. S. (2000). Contextual fear, gestalt memories, and the hippocampus. Behavioural Brain Research, 110, 73-81.

Fanselow, M. S., \& Helmstetter, F. J. (1988). Conditional analgesia, defensive freezing, and benzodiazepines. Behavioral Neuroscience, 102, 233-243.

Fendt, M. (2001). Injections of the NMDA receptor antagonist aminophosphonopentanoic acid into the lateral nucleus of the amygdala block the expression of fear-potentiated startle and freezing. The Journal of Neuroscience, 21, 4111-4115.

Fendt, M., \& Fanselow, M. S. (1999). The neuroanatomical and neurochemical basis of conditioned fear. Neuroscience and Biobehavioral Reviews, 23, 743-760.

File, S. E., Gonzalez, L. E., \& Gallant, R. (1998). Role of the basolateral nucleus of the amygdala in the formation of a phobia. Neuropsychopharmacology, 19, 397-405.

File, S. E., Zangrossi, H., Jr., Viana, M., \& Graeff, F. G. (1993). Trial 2 in the elevated plus-maze: a different form of fear? Psychopharmacology, 111, 491-494.

Fossey, M. D., Lydiard, R. B., Ballenger, J. C., Laraia, M. T., Bissette, G., \& Nemeroff, C. B. (1996). Cerebrospinal fluid corticotropinreleasing factor concentrations in patients with anxiety disorders and normal comparison subjects. Biological Psychiatry, 39, 703707. 
Fricchione, G. (2004). Clinical practice. Generalized anxiety disorder. The New England Journal of Medicine, 351, 675-682.

Gambi, F., De Berardis, D., Campanella, D., Carano, A., Sepede, G., Salini, G., et al. (2005). Mirtazapine treatment of generalized anxiety disorder: a fixed dose, open label study. Journal of Psychopharmacology, 19, 483-487.

Gerra, G., Zaimovic, A., Zambelli, U., Timpano, M., Reali, N., Bernasconi, S., et al. (2000). Neuroendocrine responses to psychological stress in adolescents with anxiety disorder. Neuropsychobiology, 42, 82-92.

Gewirtz, J. C., Falls, W. A., \& Davis, M. (1997). Normal conditioned inhibition and extinction of freezing and fear-potentiated startle following electrolytic lesions of medical prefrontal cortex in rats. Behavioral Neuroscience, 111, 712-726.

Gewirtz, J. C., McNish, K. A., \& Davis, M. (1998). Lesions of the bed nucleus of the stria terminalis block sensitization of the acoustic startle reflex produced by repeated stress, but not fear-potentiated startle. Progress in Neuro-Psychopharmacology and Biological Psychiatry, 22, 625-648.

Gewirtz, J. C., McNish, K. A., \& Davis, M. (2000). Is the hippocampus necessary for contextual fear conditioning? Behavioural Brain Research, 110, 83-95.

Geyer, M. A., \& Markou, A. (1995). Animal models of psychiatric disorders. In F. Bloom (Ed.), Psychopharmacology: the fourth generation of progress. New York: Raven.

Gleitman, L. R., \& Landau, B. (1994). The acquisition of the lexicon. Cambridge: MIT Press.

Golbin, A. Z., Kravitz, H. M., \& Keith, L. G. (2004). Sleep psychiatry. London: Parthenon.

Goodwin, R. D., Keyes, K. M., Stein, M. B., \& Talley, N. J. (2009). Peptic ulcer and mental disorders among adults in the community: the role of nicotine and alcohol use disorders. Psychosomatic Medicine, 71, 463-468.

Goodwin, R. D., \& Stein, M. B. (2002). Generalized anxiety disorder and peptic ulcer disease among adults in the United States. Psychosomatic Medicine, 64, 862-866.

Gorwood, P. (2004). Generalized anxiety disorder and major depressive disorder comorbidity: an example of genetic pleiotropy? European Psychiatry, 19, 27-33.

Gosselin, P., \& Laberge, B. (2003). Etiological factors of generalized anxiety disorder. L'Encéphale, 29, 351-361.

Graeff, F. G., Netto, C. F., \& Zangrossi, H., Jr. (1998). The elevated Tmaze as an experimental model of anxiety. Neuroscience and Biobehavioral Reviews, 23, 237-246.

Graeff, F. G., \& Zangrossi, H., Jr. (2002). Animal models of anxiety disorders. In H. A. H. D'haenen, J. A. den Boer, \& P. Willner (Eds.), Biological psychiatry (pp. 879-893). Chichester: Wiley.

Gray, T. S., Piechowski, R. A., Yracheta, J. M., Rittenhouse, P. A., Bethea, C. L., \& Van de Kar, L. D. (1993). Ibotenic acid lesions in the bed nucleus of the stria terminalis attenuate conditioned stress-induced increases in prolactin, $\mathrm{ACTH}$ and corticosterone. Neuroendocrinology, 57, 517-524.

Griebel, G. (1995). 5-Hydroxytryptamine-interacting drugs in animal models of anxiety disorders: more than 30 years of research. Pharmacology \& Therapeutics, 65, 319-395.

Grillon, C. (2002). Startle reactivity and anxiety disorders: aversive conditioning, context, and neurobiology. Biological Psychiatry, $52,958-975$.

Grillon, C., Baas, J. M., Cornwell, B., \& Johnson, L. (2006). Context conditioning and behavioral avoidance in a virtual reality environment: effect of predictability. Biological Psychiatry, 60, $752-759$.

Grillon, C., Baas, J. M., Pine, D. S., Lissek, S., Lawley, M., Ellis, V., et al. (2006). The benzodiazepine alprazolam dissociates contextual fear from cued fear in humans as assessed by fear-potentiated startle. Biological Psychiatry, 60, 760-766.
Grillon, C., Cordova, J., Levine, L. R., \& Morgan, C. A. (2003). Anxiolytic effects of a novel group: II metabotropic glutamate receptor agonist (LY354740) in the fear-potentiated startle paradigm in humans. Psychopharmacology, 168, 446-454.

Grillon, C., Cordova, J., Morgan, C. A., Charney, D. S., \& Davis, M. (2004). Effects of the beta-blocker propranolol on cued and contextual fear conditioning in humans. Psychopharmacology, $175,342-352$.

Grillon, C., Lissek, S., Rabin, S., McDowell, D., Dvir, S., \& Pine, D. S. (2008). Increased anxiety during anticipation of unpredictable but not predictable aversive stimuli as a psychophysiologic marker of panic disorder. The American Journal of Psychiatry, 165, 898-904.

Grillon, C., Pine, D. S., Lissek, S., Rabin, S., Bonne, O., \& Vythilingam, M. (2009). Increased anxiety during anticipation of unpredictable aversive stimuli in posttraumatic stress disorder but not in generalized anxiety disorder. Biological Psychiatry, 66, $47-53$.

Gros, D. F., Antony, M. M., McCabe, R. E., \& Swinson, R. P. (2009). Frequency and severity of the symptoms of irritable bowel syndrome across the anxiety disorders and depression. Journal of Anxiety Disorders, 23, 290-296.

Gue, M., Junien, J. L., \& Bueno, L. (1991). Conditioned emotional response in rats enhances colonic motility through the central release of corticotropin-releasing factor. Gastroenterology, 100, 964-970.

Guile, M. N. (1987). Differential gastric ulceration in rats receiving shocks on either fixed-time or variable-time schedules. Behavioral Neuroscience, 101, 139-140.

Härter, M. C., Conway, K. P., \& Merikangas, K. R. (2003). Associations between anxiety disorders and physical illness. European Archives of Psychiatry and Clinical Neuroscience, 253, 313-320.

Herman, J. P., \& Cullinan, W. E. (1997). Neurocircuitry of stress: central control of the hypothalamo-pituitary-adrenocortical axis. Trends in Neurosciences, 20, 78-84.

Hettema, J. M., Prescott, C. A., \& Kendler, K. S. (2001). A population-based twin study of generalized anxiety disorder in men and women. Journal of Nervous Mental Disorders, 189, 413-420.

Hoehn-Saric, R., McLeod, D. R., Funderburk, F., \& Kowalski, P. (2004). Somatic symptoms and physiologic responses in generalized anxiety disorder and panic disorder: an ambulatory monitor study. Archives of General Psychiatry, 61, 913921.

Hoehn-Saric, R., McLeod, D. R., Lee, Y. B., \& Zimmerli, W. D. (1991). Cortisol levels in generalized anxiety disorder. Psychiatry Research, 38, 313-315.

Holaway, R. M., Heimberg, R. G., \& Coles, M. E. (2006). A comparison of intolerance of uncertainty in analogue obsessivecompulsive disorder and generalized anxiety disorder. Journal of Anxiety Disorders, 20, 158-174.

Hubbard, D. T., Nakashima, B. R., Lee, I., \& Takahashi, L. K. (2007). Activation of basolateral amygdala corticotropin-releasing factor 1 receptors modulates the consolidation of contextual fear. Neuroscience, $150,818-828$.

Hunot, V., Churchill, R., Teixeira, V., \& Silva de Lima, M. (2007). Psychological therapies for generalised anxiety disorder. Cochrane Database of Systematic Reviews, CD001848.

Inoue, T., Hashimoto, S., Tsuchiya, K., Izumi, T., Ohmori, T., \& Koyama, T. (1996). Effect of citalopram, a selective serotonin reuptake inhibitor, on the acquisition of conditioned freezing. European Journal of Pharmacology, 311, 1-6.

Inoue, T., Tsuchiya, K., \& Koyama, T. (1996). Serotonergic activation reduces defensive freezing in the conditioned fear paradigm. Pharmacology, Biochemistry and Behavior, 53, 825-831. 
Izumi, T., Inoue, T., Tsuchiya, K., Hashimoto, S., Ohmori, T., \& Koyama, T. (1996). Effect of the selective CCKB receptor antagonist LY288513 on conditioned fear stress in rats. European Journal of Pharmacology, 300, 25-31.

Jones, S. V., Heldt, S. A., Davis, M., \& Ressler, K. J. (2005). Olfactory-mediated fear conditioning in mice: Simultaneous measurements of fear-potentiated startle and freezing. Behavioral Neuroscience, 119, 329-335.

Kapczinski, F., Lima, M. S., Souza, J. S., \& Schmitt, R. (2003). Antidepressants for generalized anxiety disorder. Cochrane Database of Systematic Reviews, CD003592.

Kessler, R. C., DuPont, R. L., Berglund, P., \& Wittchen, H. U. (1999). Impairment in pure and comorbid generalized anxiety disorder and major depression at 12 months in two national surveys. The American Journal of Psychiatry, 156, 1915-1923.

Kim, M., \& Davis, M. (1993). Electrolytic lesions of the amygdala block acquisition and expression of fear-potentiated startle even with extensive training but do not prevent reacquisition. Behavioral Neuroscience, 107, 580-595.

Kitaichi, Y., Inoue, T., Nakagawa, S., Izumi, T., \& Koyama, T. (2006). Effect of co-administration of subchronic lithium pretreatment and acute MAO inhibitors on extracellular monoamine levels and the expression of contextual conditioned fear in rats. European Journal of Pharmacology, 532, 236-245.

Lang, P. J., Bradley, M. M., \& Cuthbert, B. N. (1998). Emotion, motivation, and anxiety: brain mechanisms and Psychophysiology. Biological Psychiatry, 44, 1248-1263.

Lang, P. J., Davis, M., \& Ohman, A. (2000). Fear and anxiety: animal models and human cognitive Psychophysiology. Journal of Affective Disorders, 61, 137-159.

Lee, S., Wu, J., Ma, Y. L., Tsang, A., Guo, W. J., \& Sung, J. (2009). Irritable bowel syndrome is strongly associated with generalized anxiety disorder: a community study. Alimentary Pharmacology \& Therapeutics, 30, 643-651.

Li, X. B., Inoue, T., Hashimoto, S., \& Koyama, T. (2001). Effect of chronic administration of flesinoxan and fluvoxamine on freezing behavior induced by conditioned fear. European Journal of Pharmacology, 425, 43-50.

Llorca, P. M., Spadone, C., Sol, O., Danniau, A., Bougerol, T., Corruble, E., et al. (2002). Efficacy and safety of hydroxyzine in the treatment of generalized anxiety disorder: a 3-month doubleblind study. The Journal of Clinical Psychiatry, 63, 1020-1027.

Luyten, L., Casteels, C., Vansteenwegen, D., van Kuyck, K., Koole, M., Van Laere, K., et al. (2011). Bed nucleus of the stria terminalis hypermetabolism during expression of anxiety but not fear. Manuscript submitted for publication.

Luyten, L., Vansteenwegen, D., van Kuyck, K., Deckers, D., \& Nuttin, B. (2011). Optimization of a contextual conditioning protocol for rats using combined measurements of startle amplitude and freezing: The effects of shock intensity and different types of conditioning. Journal of Neuroscience Methods, 194, 305-311.

Luyten, L., Vansteenwegen, D., van Kuyck, K., \& Nuttin, B. (2011). Optimization of a chronic contextual conditioning protocol in rats: The effect of different numbers of explicitly unpaired toneshock presentations on freezing time and startle amplitude. Manuscript submitted for publication.

Lyonfields, J. D., Borkovec, T. D., \& Thayer, J. F. (1995). Vagal tone in generalized anxiety disorder and the effects of aversive imagery and worrisome thinking. Behavior Therapy, 26, 457466.

Mackintosh, M. A., Gatz, M., Wetherell, J. L., \& Pedersen, N. L. (2006). A twin study of lifetime generalized anxiety disorder (GAD) in older adults: genetic and environmental influences shared by neuroticism and GAD. Twin Research and Human Genetics, 9, 30-37.
Maier, S. F., \& Seligman, M. E. P. (1976). Learned helplessnesstheory and evidence. Journal of Experimental Psychology: General, 105, 3-46.

Maki, Y., Inoue, T., Izumi, T., Muraki, I., Ito, K., Kitaichi, Y., et al. (2000). Monoamine oxidase inhibitors reduce conditioned fear stress-induced freezing behavior in rats. European Journal of Pharmacology, 406, 411-418.

Mantella, R. C., Butters, M. A., Amico, J. A., Mazumdar, S., Rollman, B. L., Begley, A. E., et al. (2008). Salivary cortisol is associated with diagnosis and severity of late-life generalized anxiety disorder. Psychoneuroendocrinology, 33, 773-781.

Marschner, A., Kalisch, R., Vervliet, B., Vansteenwegen, D., \& Buchel, C. (2008). Dissociable roles for the hippocampus and the amygdala in human cued versus context fear conditioning. The Journal of Neuroscience, 28, 9030-9036.

Mathew, S. J., Mao, X., Coplan, J. D., Smith, E. L., Sackeim, H. A., Gorman, J. M., et al. (2004). Dorsolateral prefrontal cortical pathology in generalized anxiety disorder: a proton magnetic resonance spectroscopic imaging study. The American Journal of Psychiatry, 161, 1119-1121.

Mathew, S. J., Price, R. B., Mao, X., Smith, E. L., Coplan, J. D., Charney, D. S., et al. (2008). Hippocampal $N$-acetylaspartate concentration and response to riluzole in generalized anxiety disorder. Biological Psychiatry, 63, 891-898.

McLeod, D. R., Hoehn-Saric, R., Porges, S. W., Kowalski, P. A., \& Clark, C. M. (2000). Therapeutic effects of imipramine are counteracted by its metabolite, desipramine, in patients with generalized anxiety disorder. Journal of Clinical Psychopharmacology, 20, 615-621.

McNish, K. A., Gewirtz, J. C., \& Davis, M. (1997). Evidence of contextual fear after lesions of the hippocampus: a disruption of freezing but not fear-potentiated startle. The Journal of Neuroscience, 17, 9353-9360.

Menard, J., \& Treit, D. (1999). Effects of centrally administered anxiolytic compounds in animal models of anxiety. Neuroscience and Biobehavioral Reviews, 23, 591-613.

Mendels, J., Krajewski, T. F., Huffer, V., Taylor, R. J., Secunda, S., Schless, A., et al. (1986). Effective short-term treatment of generalized anxiety disorder with trifluoperazine. The Journal of Clinical Psychiatry, 47, 170-174.

Michelson, D., Levine, L. R., Dellva, M. A., Mesters, P., Schoepp, D. D., Dunayevich, E., et al. (2005). Clinical studies with mGlu2/3 agonists: LY354740 compared with placebo in patients with generalized anxiety disorder. Neuropharmacology, 49(Suppl. 1), $1-279$.

Milanov, I. (2007). Clinical and electromyographic characteristics of tremor in patients with generalized anxiety disorder. Electromyography and Clinical Neurophysiology, 47, 3-9.

Mineka, S., \& Hendersen, R. W. (1985). Controllability and predictability in acquired motivation. Annual Review of Psychology, 36, 495-529.

Mineka, S., \& Kihlstrom, J. F. (1978). Unpredictable and uncontrollable events: a new perspective on experimental neurosis. Journal of Abnormal Psychology, 87, 256-271.

Mineka, S., \& Zinbarg, R. (2006). A contemporary learning theory perspective on the etiology of anxiety disorders: It's not what you thought it was. The American Psychologist, 61, 10-26.

Mula, M., Pini, S., \& Cassano, G. B. (2007). The role of anticonvulsant drugs in anxiety disorders: a critical review of the evidence. Journal of Clinical Psychopharmacology, 27, 263272.

Narrow, W. E., Rae, D. S., Robins, L. N., \& Regier, D. A. (2002). Revised prevalence estimates of mental disorders in the United States: using a clinical significance criterion to reconcile 2 surveys' estimates. Archives of General Psychiatry, 59, 115123. 
Nishikawa, H., Inoue, T., Masui, T., Izumi, T., \& Koyama, T. (2007). Effects of cytochrome P450 (CYP) 3A4 inhibitors on the anxiolytic action of tandospirone in rat contextual conditioned fear. Progress in Neuro-Psychopharmacology and Biological Psychiatry, 31, 926-931.

Nishitsuji, K., To, H., Murakami, Y., Kodama, K., Kobayashi, D., Yamada, T., et al. (2004). Tandospirone in the treatment of generalised anxiety disorder and mixed anxiety-depression: results of a comparatively high dosage trial. Clinical Drug Investigation, 24, 121-126.

Noel, F., Stevens, G., \& Bradford, D. (1996). Flesinoxan treatment of generalized anxiety disorder: a fixed dose, placebo-controlled trial [Abstract]. European Neuropsychopharmacology, 6(Suppl. 4), 144.

Nutt, D., \& Malizia, A. (2006). Anxiety and OCD - the chicken or the egg? Journal of Psychopharmacology, 20, 729-731.

Ohmura, Y., Yamaguchi, T., Izumi, T., Matsumoto, M., \& Yoshioka, M. (2008). Corticotropin releasing factor in the median raphe nucleus is involved in the retrieval of fear memory in rats. European Journal of Pharmacology, 584, 357-360.

Orman, R., \& Stewart, M. (2007). Hemispheric differences in protein kinase $\mathrm{C}$ betaII levels in the rat amygdala: baseline asymmetry and lateralized changes associated with cue and context in a classical fear conditioning paradigm. Neuroscience, 144, 797807.

Paulesu, E., Sambugaro, E., Torti, T., Danelli, L., Ferri, F., Scialfa, G., et al. (2010). Neural correlates of worry in generalized anxiety disorder and in normal controls: a functional MRI study. Psychological Medicine, 40, 117-124.

Pezze, M. A., Bast, T., \& Feldon, J. (2003). Significance of dopamine transmission in the rat medial prefrontal cortex for conditioned fear. Cerebral Cortex, 13, 371-380.

Pfeffer, C. R., Altemus, M., Heo, M., \& Jiang, H. (2007). Salivary cortisol and psychopathology in children bereaved by the September 11, 2001 terror attacks. Biological Psychiatry, 61, 957-965.

Phillips, R. G., \& LeDoux, J. E. (1994). Lesions of the dorsal hippocampal formation interfere with background but not foreground contextual fear conditioning. Learning \& Memory, $1,34-44$

Pitts, M. W., Todorovic, C., Blank, T., \& Takahashi, L. K. (2009). The central nucleus of the amygdala and corticotropin-releasing factor: insights into contextual fear memory. The Journal of Neuroscience, 29, 7379-7388.

Pollack, M. H. (2009). Refractory generalized anxiety disorder. The Journal of Clinical Psychiatry, 70(Suppl. 2), 32-38.

Pollack, M. H., Simon, N. M., Zalta, A. K., Worthington, J. J., Hoge, E. A., Mick, E., et al. (2006). Olanzapine augmentation of fluoxetine for refractory generalized anxiety disorder: a placebo controlled study. Biological Psychiatry, 59, 211-215.

Pomara, N., Willoughby, L. M., Sidtis, J. J., Cooper, T. B., \& Greenblatt, D. J. (2005). Cortisol response to diazepam: Its relationship to age, dose, duration of treatment, and presence of generalized anxiety disorder. Psychopharmacology, 178, 1-8.

Portugal, G. S., \& Gould, T. J. (2007). Bupropion dose-dependently reverses nicotine withdrawal deficits in contextual fear conditioning. Pharmacology, Biochemistry and Behavior, 88, 179187.

Ray, W. J., Molnar, C., Aikins, D., Yamasaki, A., Newman, M. G., Castonguay, L., et al. (2009). Startle response in generalized anxiety disorder. Depression and Anxiety, 26, 147-154.

Rescorla, R. A. (1969). Conditioned inhibition of fear. In N. J. Mackintosh \& W. K. Honig (Eds.), Fundamental issues in associative learning. Halifax: Dalhousie University Press. pp. 65-89

Resstel, L. B., Alves, F. H., Reis, D. G., Crestani, C. C., Correa, F. M., \& Guimaraes, F. S. (2008). Anxiolytic-like effects induced by acute reversible inactivation of the bed nucleus of stria terminalis. Neuroscience, 154, 869-876.

Resstel, L. B., Joca, S. R., Moreira, F. A., Correa, F. M., \& Guimaraes, F. S. (2006). Effects of cannabidiol and diazepam on behavioral and cardiovascular responses induced by contextual conditioned fear in rats. Behavioural Brain Research, 172, 294-298.

Rickels, K., DeMartinis, N., \& Aufdembrinke, B. (2000). A doubleblind, placebo-controlled trial of abecarnil and diazepam in the treatment of patients with generalized anxiety disorder. Journal of Clinical Psychopharmacology, 20, 12-18.

Rickels, K., Downing, R., Schweizer, E., \& Hassman, H. (1993). Antidepressants for the treatment of generalized anxiety disorder. A placebo-controlled comparison of imipramine, trazodone, and diazepam. Archives of General Psychiatry, 50, 884-895.

Riedel, G., Harrington, N. R., Kozikowski, A. P., Sandager-Nielsen, K., \& Macphail, E. M. (2002). Variation of CS salience reveals group II mGluR-dependent and -independent forms of conditioning in the rat. Neuropharmacology, 43, 205-214.

Risbrough, V. B., \& Stein, M. B. (2006). Role of corticotropin releasing factor in anxiety disorders: a translational research perspective. Hormones and Behavior, 50, 550-561.

Roemer, L., Molina, S., Litz, B. T., \& Borkovec, T. D. (1996). Preliminary investigation of the role of previous exposure to potentially traumatizing events in generalized anxiety disorder. Depression and Anxiety, 4, 134-138.

Ron, M. A., \& Robbins, T. W. (Eds.). (2003). Disorders of brain and mind 2. Cambridge: Cambridge University Press.

Rynn, M., Russell, J., Erickson, J., Detke, M. J., Ball, S., Dinkel, J., et al. (2008). Efficacy and safety of duloxetine in the treatment of generalized anxiety disorder: a flexible-dose, progressive-titration, placebo-controlled trial. Depression and Anxiety, 25, 182-189.

Santos, J. M., Gargaro, A. C., Oliveira, A. R., Masson, S., \& Brandao, M. L. (2005). Pharmacological dissociation of moderate and high contextual fear as assessed by freezing behavior and fearpotentiated startle. European Neuropsychopharmacology, 15, 239-246.

Santos, J. M., Martinez, R. C., \& Brandao, M. L. (2006). Effects of acute and subchronic treatments with fluoxetine and desipramine on the memory of fear in moderate and high-intensity contextual conditioning. European Journal of Pharmacology, 542, 121-128.

Seligman, M. E. (1968). Chronic fear produced by unpredictable electric shock. Journal of Comparative and Physiological Psychology, 66, 402-411.

Shekhar, A., Truitt, W., Rainnie, D., \& Sajdyk, T. (2005). Role of stress, corticotrophin releasing factor (CRF) and amygdala plasticity in chronic anxiety. Stress, 8, 209-219.

Simon, N. M., Zalta, A. K., Worthington, J. J., 3rd, Hoge, E. A., Christian, K. M., Stevens, J. C., et al. (2006). Preliminary support for gender differences in response to fluoxetine for generalized anxiety disorder. Depression and Anxiety, 23, 373-376.

Snyderman, S. H., Rynn, M. A., \& Rickels, K. (2005). Open-label pilot study of ziprasidone for refractory generalized anxiety disorder. Journal of Clinical Psychopharmacology, 25, 497-499.

Sramek, J. J., Zarotsky, V., \& Cutler, N. R. (2002). Generalised anxiety disorder: treatment options. Drugs, 62, 1635-1648.

Stein, M. B. (2009). Neurobiology of generalized anxiety disorder. The Journal of Clinical Psychiatry, 70(Suppl. 2), 15-19.

Sullivan, G. M., Apergis, J., Bush, D. E., Johnson, L. R., Hou, M., \& Ledoux, J. E. (2004). Lesions in the bed nucleus of the stria terminalis disrupt corticosterone and freezing responses elicited by a contextual but not by a specific cue-conditioned fear stimulus. Neuroscience, 128, 7-14.

Tadic, A., Rujescu, D., Szegedi, A., Giegling, I., Singer, P., Möller, H.-J., et al. (2003). Association of a MAOA gene variant with generalized anxiety disorder, but not with panic disorder or major depression. American Journal of Medical Genetics Part B, 117B, 1-6. 
Takahashi, T., Morinobu, S., Iwamoto, Y., \& Yamawaki, S. (2006). Effect of paroxetine on enhanced contextual fear induced by single prolonged stress in rats. Psychopharmacology, 189, 165-173.

Thayer, J. F., Friedman, B. H., \& Borkovec, T. D. (1996). Autonomic characteristics of generalized anxiety disorder and worry. Biological Psychiatry, 39, 255-266.

Tiba, P. A., Oliveira, M. G., Rossi, V. C., Tufik, S., \& Suchecki, D. (2008). Glucocorticoids are not responsible for paradoxical sleep deprivation-induced memory impairments. Sleep, 31, 505-515.

Turk, C. L., Heimberg, R. G., Luterek, J. A., Mennin, D. S., \& Fresco, D. M. (2005). Emotion dysregulation in generalized anxiety disorder: a comparison with social anxiety disorder. Cognitive Therapy and Research, 29, 89-106.

Tyrer, P. (1999). Anxiety: a multidisciplinary review. London: Imperial College Press.

Tyrer, P., \& Baldwin, D. (2006). Generalised anxiety disorder. Lancet, $368,2156-2166$.

Ulrich-Lai, Y. M., \& Herman, J. P. (2009). Neural regulation of endocrine and autonomic stress responses. Nature Reviews. Neuroscience, 10, 397-409.

Varia, I., \& Rauscher, F. (2002). Treatment of generalized anxiety disorder with citalopram. International Clinical Psychopharmacology, 17, 103-107.

Verleye, M., \& Gillardin, J. M. (2004). Effects of etifoxine on stressinduced hyperthermia, freezing behavior and colonic motor activation in rats. Physiology \& Behavior, 82, 891-897.

Walker, D. L., Toufexis, D. J., \& Davis, M. (2003). Role of the bed nucleus of the stria terminalis versus the amygdala in fear, stress, and anxiety. European Journal of Pharmacology, 463, 199-216.

Willner, P. (1986). Validation criteria for animal models of human mental disorders: learned helplessness as a paradigm case.
Progress in Neuro-Psychopharmacology and Biological Psychiatry, 10, 677-690.

Willner, P. (1997). Validity, reliability and utility of the chronic mild stress model of depression: a 10 -year review and evaluation. Psychopharmacology, 134, 319-329.

Willner, P., \& Mitchell, P. J. (2002). The validity of animal models of predisposition to depression. Behavioural Pharmacology, 13, 169-188.

Wittchen, H. U., Carter, R. M., Pfister, H., Montgomery, S. A., \& Kessler, R. C. (2000). Disabilities and quality of life in pure and comorbid generalized anxiety disorder and major depression in a national survey. International Clinical Psychopharmacology, 15, 319-328.

Woody, S., \& Rachman, S. (1994). Generalized anxiety disorder (GAD) as an unsuccessful search for safety. Clinical Psychology Review, 14, 743-753.

Wu, J. C., Buchsbaum, M. S., Hershey, T. G., Hazlett, E., Sicotte, N., \& Johnson, J. C. (1991). PET in generalized anxiety disorder. Biological Psychiatry, 29, 1181-1199.

Zanoveli, J. M., Ferreira-Netto, C., \& Brandao, M. L. (2007). Conditioned place aversion organized in the dorsal periaqueductal gray recruits the laterodorsal nucleus of the thalamus and the basolateral amygdala. Experimental Neurology, 208, 127-136.

We acknowledge the financial support of the Research FoundationFlanders (FWO) (project G.0729.09 N). L.L. is a doctoral fellow of the FWO. 